\title{
Assessing Chinese Consumers' Likelihood To Adopt Self-Service Technologies
}

Kevin M. Elliott, Ph.D., Minnesota State University, Mankato, USA

Juan (Gloria) Meng, Ph.D., Minnesota State University, Mankato, USA

\begin{abstract}
The proliferation of new self-service technology in retailing suggests a need to assess the extent to which consumers are ready and willing to actually use the technology. This study examines the influence that the dimensions of the Technology Readiness Index (TRI) has on the propensity of consumers in China, one of the fastest growing economies in the world, to use self-service technology to complete retail transactions. Cluster analysis was also used to classify Chinese consumers into consumer types based on their TRI scores. The findings indicate that the dimensions of TRI impacts consumer types differently with respect to influencing the likelihood of using self-service technology. Implications of the consumer classifications are also discussed.
\end{abstract}

Keywords: Chinese consumers, self-service technologies, technology readiness

\section{INTRODUCTION}

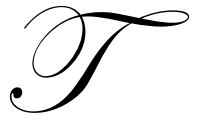

he importance of self-service technologies in the retail environment has grown significantly over the last decade. Technology-based interactions are also expected to become an increasingly important ingredient for long-term success in the delivery of services for retailers in the future (Bitner et al., 2000). Examples of innovations driving the increased usage of self-service technologies include such things as online shopping (Childers et al., 2001) and self-scanning systems (Dabholkar et al., 2003).

While the use of self-service technologies in the retail setting within the United States has seen an increasing level of acceptance by consumers, the same cannot be said in various countries throughout the world. Some cultures have been very receptive to new retail technology, while others have been slow to accept and adopt it. Recent studies have shown that cultural characteristics and values can influence technology acceptance ( Lee et al., 2007: Srite et al., 2006). These cultural influences play a critical role in defining the social context within which consumers behave.

Thanks to a rapidly growing middle class, consumer consumption in China is expected to rise sharply by 2015 , driven by the expanding consumer group of "upper aspirants" whose household income is between $\$ 40 \mathrm{~K}$ $\$ 100 \mathrm{~K}$ (McKinsey Group, 2006). The 11.5\% increase in economic output for the three months ending September 2007 has China on track to surpass Germany as the world's third-largest economy by early 2008 (International Herald Tribune, 2007). Moreover, China is expected to become the second largest consumer market by 2015 (Boston Consulting Group, 2007). Although many of the self-service technologies currently found in the U.S. retail marketplace are not commonly available in China, due to the rapid growth, it is seemingly only a matter of time until most of the innovative self-service technologies found in the U.S. are also offered to Chinese consumers.

Parasuraman (2000) proposes a "technology readiness index" (TRI), which measures the "propensity to embrace and use new technologies for accomplishing goals in home life and at work." The TRI identifies four dimensions of technology belief that impact an individual's level of techno-readiness. Two of the dimensions are contributors and two are inhibitors of technology adoption. The contributors are: 1) Optimism - the degree to which individuals believe that technology can benefit their lives and give them more control over their life, and 2) Innovativeness - a natural desire to experiment with new technologies, as well as to be a thought leader. The inhibitors are: 1) Discomfort - a feeling of lacking both control over technology and the confidence in making the 
technology work, and 2) Insecurity - a need for assurance that a technology-based product, service or process will operate reliably and accurately. Research has shown that consumers who are "ready" to use self-service technology are more likely to try it.

The purpose of this study is to assess the relative importance of the four dimensions of the TRI with respect to determining Chinese consumers' likelihood to use self-service technology to complete retail transactions. Consumer classifications will also be identified that hopefully will be beneficial to marketers when targeting specific types of Chinese consumers.

\section{ADOPTION OF NEW SELF-SERVICE TECHNOLOGIES}

Innovation diffusion is generally defined as the process by which the adoption of an innovation spreads. The assumption is that not all consumers will adopt a new innovation at the same rate. The widely accepted "Rogers' curve" identifies five types of adopting consumers based on the relative timing of their adoption of new products (Rogers 1995). The categories of adopters include Innovators, Early Adopters, Early Majority, Late Majority, and Laggards. The Innovators are characterized as venturesome and are the first to adopt a new idea or product, while the Laggards tend to be suspicious of new products and are the last group of consumers to adopt a new innovation.

According to McDonald et al., (2003), innovation adoption is of interest in marketing because of the potential to increase the efficiency of new product marketing efforts:

- $\quad$ by identifying those members of the target market most likely to adopt early,

- $\quad$ by shedding light on the nature and size of the potential market for new products,

- by providing insight into how to increase the "innovativeness" of a market, and

- $\quad$ by indicating the time of adoption by various proportions of the population.

The speed at which new technology is diffused throughout a target market is dependent upon the following characteristics: 1) relative advantage it offers over existing products, 2) compatibility with existing values and needs of potential adopters, 3) complexity in understanding and using a new product, 4) trialability of the new technology on a limited basis, and 5) observability to others (Rogers 1995).

Not all consumers embrace self-service technology in the retail environment today. Some consumers actively seek out self-scanning checkouts, online banking services, and Internet shopping options. Other consumers, however, intentionally avoid such self-service technologies. For example, some retailers who are using in-store Internet kiosks are finding out that not all consumers are interested in using the new technology (Mearian, 2001). Getting consumers to try a new self-service technology for the first time is a critical first step in getting them to embrace the technology. Not only must consumers change their behaviors, but they must also become co- producers of the service, with responsibility for delivery of the service and for their own satisfaction (Bendapudi and Leone, 2003).

The extent to which consumers desire and are willing to use self-service technologies is commonly influenced by such factors as consumer attitudes toward specific technologies (Curran et al., 2003) and the level of technology anxiety exhibited by consumers (Meuter et al., 2003). Similarly, Bobbitt and Dabholkar (2001) report that consumer attitudes have a strong and direct effect on intentions to use technology-based self-service.

Mick and Fournier (1998) argue that consumers can simultaneously exhibit positive feelings (such as intelligence or efficacy) and negative feelings (such as ignorance or ineptitude) towards new technology. Similarly, Venkatesh (2000) found that "computer playfulness" and "computer anxiety" serve as anchors that users employ in forming perceptions of ease of use about new technology. Therefore, consumers can seemingly be arrayed along a hypothetical technology-belief continuum with their position on the continuum correlating with their propensity to embrace technology (Parasuraman, 2000). 
Studies have also shown that perceived performance satisfaction, usefulness, self-efficacy, inherent novelty seeking, need for interaction with a service employee, self-consciousness and social influence may impact a consumers attitude toward using technology (Dabholkar and Bagozzi, 2002; Davis et al., 1989, 1992; Ellen et al., 1991). In addition, some consumers have shown a preference to self-service technology because of ease of use or because it helps them avoid interaction with retail employees (Dabholkar, 1996; Meuter et al., 2000). Not surprisingly, Szymanski and Hise (2000) also found convenience to be a key factor influencing e-satisfaction with technology use in retailing.

Many retailers today are investing in self-service technology to improve service quality and to cut costs (Weijters et al., 2007). Self-service technologies allow retailers to standardized their interaction with consumers, which results in a more consistent service atmosphere independent of employees' personality and mood (Hsieh et al., 2004). In addition, self-service technologies allow consumers to be productive resources involved in the service delivery, thus allowing retailers to handle demand fluctuations without expensive adjustment of employee levels (Curran et al., 2003).

Self-service technology is likely to become increasingly more important as retailers across the globe continue to strive to minimize costs and maximize service in order to remain competitive in the marketplace. Common self-service technologies being used today by retailers include: 1) telephone-based technologies and interactive voice response systems, 2) direct online connections and Internet-based interfaces, 3) interactive freestanding kiosks, and 4) video or CD technologies (Bitner et al., 2002). Specific examples of self-services would include automated hotel checkout, banking via ATMs or by telephone, self-scanning checkouts at grocery or discount stores, Internet shopping, and paying bills online.

Several studies have looked at user profiles to explain receptiveness to self-service technologies. For example, Barczak, Ellen, and Pilling (1997) looked at consumers' use of ATMs, automatic deposits/withdrawals, and telephone banking and identified the consumer profiles of security conscious, maximizers, instant gratifiers, and hassle avoiders. Other studies have looked at age profiles of consumers to predict the adoption rate of consumerrelated technologies (Gilly and Zeithaml, 1985). The desire to use self-service technologies is also often influenced by such factors as consumer attitudes toward specific technologies (Curran et al., 2003) and the level of technology anxiety exhibited by consumers (Meuter et al., 2003). Both desire to use and anxiety toward technology can be influenced by culture.

\section{Cultural Influence On Technology Use}

Cultural differences have been observed and reported in a number of studies to have a significant impact on consumer decision-making and individual behavior (Erumban and de Jong 2006; Leo and Hartel 2005; Singh 2006). Moreover, Strite and Karahanna (2006) found that espoused national cultural values moderated the relationships between perceived ease of use of technology and behavioral intentions toward the technology, and between social norms and behavior intentions.

The U.S. and China have been shown to be culturally very different (Hofstede, 1980). The Chinese culture is characterized as a highly collective society that prefers to conform to the norms of society and appears less likely to accept new retail self-service technology (i.e., self-scanning check-outs, Internet shopping, paying bills online), than an individualistic society (i.e., American society) that is inclined to make individual choices and therefore seemingly more likely to be innovative and adopt new ideas. The Chinese culture also is characterized as a high power distance society, thus not likely to be open to new ideas because of the lack of information available.

In addition, the Chinese culture is viewed as a long-term society that values patience and traditional values. Patience and traditional values do not lend themselves to the quick adoption of new technology. However, a shortterm orientation and the fast pace lifestyle of the typical American does suggest a greater likelihood of adopting new technologies. The U.S. and Chinese cultures are relative similar in uncertainty avoidance and masculinity as compared to other countries throughout the world, thus no differences are distinguishable on these two cultural dimensions. 
Therefore, it is important to explore Chinese consumers' attitudes and behaviors towards the use of new technology, and to provide marketers with a better understanding of how best to enhance the adoption of self-service technology within the Chinese marketplace. China offers an excellent opportunity for growth and profit for many retailers who provide self-service options to complete retail transactions. The challenge is to assess Chinese consumers' readiness and willingness to use the new technology.

\section{METHODOLOGY}

Technology readiness was assessed through the use of the 36-item Technology Readiness Index (TRI) scale developed by Parasuraman (2000). (See Appendix) The TRI is a Likert type scale with responses ranging from "Strongly Agree" (5) to "Strongly Disagree" (1). The TRI measures an individual's propensity to adopt and use innovative technology by assessing how "techno-ready" individuals are. In addition, the TRI helps explains how and why different individuals adopt technology. The TRI does this by looking at both forces that attract consumers to innovative products and forces that may repel them away from new products.

Chinese consumers" "likelihood to use self-service technology" was operationalized using a 5-item, 7-point Likert-type scale. The five retail self-service technology items selected were based on: 1) previous research that identified common self-service technologies found in the retail environment (Bitner et al., 2002; Meuter et al., 2005), and 2) common technology interfaces found in the marketplace (online/Internet interfaces and interactive freestanding kiosks/checkouts). Table 1 identifies the five areas of self-service technologies that were assessed for likelihood of use. The remaining three items comprising the questionnaire were demographic questions that were used for classification purposes.

Table 1

Likelihood of Using Self-Service Technology

1. How likely are you to use bank ATM services?

2. How likely are you to shop online for retail products?

3. How likely are you to use self-service checkouts at retail stores?

4. How likely are you to purchase e-airline tickets?

5. How likely are you to pay bills online?

*Likert-typed scale - ("1" = Very Unlikely) ("7" = Very Likely)

\section{Data Collection}

Data were collected using a convenience sample of 219 Chinese students enrolled in a large regional university in China. The sample consisted of $70(32 \%)$ male and 149 (68\%) female respondents. Students were surveyed via a personal questionnaire. College students were deemed as viable respondents in this study because Chinese college students are active and often well informed consumers. They are likely to be exposed to and given the opportunity to use new self-service technologies before many other individuals within the Chinese general population. Moreover, China's teenagers and "twentysomethings" enjoy significant spending power because of generous relatives, and are eager to try many Western goods that are flowing into China (Boston Consulting Group, 2007).

\section{Data Analysis}

LISREL 8.72 was used to purify the measurement of the four factors comprising the TRI scale. Three types of information were considered in assessing measurement fit: chi-square, measurement error (RMSEA = root-meansquare error of approximation and RMR = root mean-square residual), and fit indices (GFI = Goodness of Fit Index, CFI = Comparative Fit Index, IFI $=$ Incremental Fit Index, NNFI $=$ Non-Normed Fit Index, and NFI $=$ Normed Fit Index).

The resulting reduced item factor scores for the four dimensions of TRI scale were then used to conduct cluster analysis to identify Chinese consumer segments. ANOVA was utilized to test for mean differences in the 
four factors comprising the TRI scale across the consumer cluster groups. Consumer profiles of the resulting clusters were also developed and analyzed.

Sum scores for all respondents were also calculated for each of the four dimensions (Optimism, Innovativeness, Insecurity, and Discomfort) comprising the reduced item TRI scale. Sum scores for the five-item "Likely to Use Self-Service Technology" scale were also computed for all respondents. Stepwise regression analysis was used, with the four dimensions of the TRI scale as the independent variables and the sum score of the "Likely to Use Self-Service Technology" as the dependent variable in order to assess the relative importance of the four dimensions of the TRI scale in predicting "likelihood of using self-service technology" for the consumer groups identified in the cluster analysis.

\section{RESULTS}

\section{Purification Of The TRI}

Using LISREL 8.72, structural equation methodology was used to purify the TRI scale for Chinese consumers. The results of eliminating items with weak factor loading (below .50) and dubious meanings are shown in Table 2. A total of 15 items remained in the measurement of the four factors comprising the TRI scale. The chisquare statistic of 1,442.5 was significant at 105 Degrees of Freedom, however, all other fit indices demonstrate a good measurement fit. The fit indices of CFI, IFI, and NNFI were all high at .93 , .93, and .91 respectively. In addition, the root mean square error of approximation (RMSEA) and the root mean square residuals (RMR) were both relatively low at .07 and .06 respectively. Therefore, the measurement model of 15 items was accepted for further anlaysis. All statistics support the measurement quality given a large sample and the number of indicators (Anderson and Gerbing, 1988).

Table 2

Reduced Technology Readiness Index Measurement Scale

\section{Optimism (Cronbach's $\alpha=$.76)}

1. Technology gives people more control over their daily lives.

2. I prefer to use the most advanced technology available.

3. I like the idea of doing business via computers because I am not limited to regular business hours.

4. Technology makes me more efficient in my occupation.

5. Technology gives me more freedom of mobility.

\section{Innovativeness (Cronbach's $\alpha=.64)$}

1. In general, I am among the first in my circle of friends to acquire new technology when it appears.

2. I can usually figure out new high-tech products and services without help from others.

3. I keep up with the latest technological developments in my areas of interest.

\section{Insecurity (Cronbach's $\alpha=.64)$}

1. If I provide information to a machine or over the Internet, I can never be sure it really gets to the right place.

2. I do not consider it safe giving out a credit card number over a computer.

3. I do not consider it safe to do any kind of financial business online.

4. Any business transaction I do electronically should be confirmed later with something in writing.

\section{Discomfort (Cronbach's $\alpha=.54)$}

1. There should be caution in replacing important people-tasks with technology because new technology can break-down or get disconnected.

2. Many new technologies have health or safety risks that are not discovered until after people have used them.

3. New technology makes it too easy for governments and companies to spy on people. 


\section{Cluster Analysis}

\section{1) Technology Readiness Index Cluster Analysis}

A hierarchical cluster analysis was conducted on the four factor scores comprising the reduced item TRI scale. Agglomeration schedule and Ward's method were utilized. Different iterations of consumer cluster solutions were attempted, with a three-cluster solution eventually accepted. ANOVA was utilized to test for mean differences in the four factors comprising the TRI scale across the three-cluster solution. The results are presented in Table 3. The findings show that there are significant differences in the TRI mean factor scores across the three consumer clusters.

Table 3

ANOVA on TRI Factors Across Consumer Clusters (5-Point Scale)

\begin{tabular}{|c|c|c|c|c|c|}
\hline $\begin{array}{c}\text { TR } \\
\text { Factors }\end{array}$ & $\begin{array}{c}\text { Cluster 1 } \\
\mathbf{( 2 9 \% )}\end{array}$ & $\begin{array}{c}\text { Cluster_2 } \\
\mathbf{( 5 0 \% )}\end{array}$ & $\begin{array}{c}\text { Cluster_3 } \\
\mathbf{( 2 1 \% )}\end{array}$ & $\begin{array}{c}\text { F } \\
\text { Value }\end{array}$ & $\begin{array}{c}\text { P } \\
\text { Value }\end{array}$ \\
\hline Optimism & 4.08 & 3.35 & 4.02 & 61.96 & .000 \\
\hline Innovation & 3.10 & 2.69 & 3.65 & 43.69 & .000 \\
\hline Insecure & 2.97 & 3.48 & 4.05 & 49.80 & .000 \\
\hline Discomfort & 3.77 & 3.50 & 4.17 & 26.60 & .000 \\
\hline
\end{tabular}

Using the mean factor scores, the following three clusters were identified:

1) Receptive consumer - (Cluster $1-29 \%$ of sample). Receptive consumers are very optimistic that technology can be beneficial in their lives. Moreover, they feel that new technology is safe regarding privacy issues. They also appear to be relatively innovative and willing to try new technology early, however, they have a moderate discomfort level regarding risks of break-downs and potential health risks associated with using new technology.

2) Unconvinced consumer - (Cluster $2-50 \%$ of sample). Unconvinced consumers are late majority type consumers when it comes to adopting new technology and comprise the largest segment of the consumer sample. They tend not to try new technology, primarily because they are not convinced that most technology can be beneficial and useful in their lives. They also have a fairly high level of discomfort with the technology they do use, and feel somewhat insecure about new technology in terms of reliability and accuracy. They tend to have the attitude of "show me why I should try something new."

3) Adventurous consumer - (Cluster $3-21 \%$ of sample). Adventurous consumers are also optimistic about the potential benefits of new technology. They appear to be the most innovative consumer group, even though they lack both the confidence in themselves to make the technology work correctly and the assurance that the technology is reliable. They seemingly yield to the desire to use new technology despite the fact they don't feel comfortable using the new technology or perceive that it is especially reliable. This consumer group comprises the smallest segment of the consumer sample.

\section{2) Profiling Clusters Using Self-Service Technology Usage Variables}

In order to further analyze the three consumer clusters, responses to the "likelihood of usage" for the five types of self-service technologies assessed in this study were recoded from numerical data to categorical data. Respondents who answered "5" (Very Likely) and "4" (Likely) to use a specific type of self-service technology were classified into the "Yes" group. Respondents who answered "3" (Neutral) were classified into the "Neutral" group. Finally, respondents who answered "2" (Unlikely) and "1" (Very Unlikely) were classified into the "No" group.

Table 4 identifies the distribution of cluster members for each of the five types of self-service technologies after the recoding of responses. The findings show that Receptive consumers had a significantly higher percentage of "Yes" responses, as compared to the total sample, in four out of the five self-service technology categories. The percentages for this group were as follows: ATMs (90.6\% vs. $78.1 \%$ for total sample), shopping online ( $82.5 \%$ vs. 
$67.6 \%$ for total sample, using self-service checkouts (77.8\% vs. $60.7 \%$ for total sample), and paying bills online $(79.4 \%$ vs. $57.5 \%)$. There was not a significant difference in responses to the purchasing of e-airline tickets among the three consumers groups when compared to the total sample.

\section{Predicting Likelihood To Use Self-Service Technology}

In order to further analyze the differences among the three groups of consumers identified above, regression analysis was utilized to assess the relative importance of the four factors comprising the TRI scale in predicting the likelihood of using self-service technology to complete retail transactions for each of the three consumer groups. Although not an absolute test for the importance for each predictor, standardized beta coefficients are often useful in determining the relative importance of independent variables in predicting dependent variables.

Table 5 shows the relative importance of the four factors of the TRI scale in predicting the likelihood of using self-service technology for the Receptive, Unconvinced, and Adventurous Consumers. For the Receptive Consumer, Optimism, Insecurity, and Discomfort were all significant predictors of likelihood to use selfservice technologies within the retail environment. Optimism appears to be the strongest predictor of using new technology for this type of consumer (beta $=.348$ ), followed by Insecurity (beta $=-.341$ ) and Discomfort $($ beta $=$ .293). Innovativeness, the desire to experiment with new technologies, was not a significant predictor.

Table 4

Chi-Square Analysis By Type of

Self-Service Technology Usage

\begin{tabular}{|c|c|c|c|c|c|c|}
\hline & $\begin{array}{c}\text { Total } \\
\text { Sample } \\
(\mathrm{n}=219)\end{array}$ & $\begin{array}{l}\text { Receptive } \\
\text { Consumer } \\
(\mathrm{n}=63)\end{array}$ & $\begin{array}{c}\text { Unconvinced } \\
\text { Consumer } \\
(\mathrm{n}=110)\end{array}$ & $\begin{array}{c}\text { Adventurous } \\
\text { Consumer } \\
(\mathrm{n}=46)\end{array}$ & $\begin{array}{c}\mathrm{X}^{2} \\
\text { Value }\end{array}$ & Sign. \\
\hline 1) ATM & & & & & 9.33 & $.053 *$ \\
\hline Yes & 78.1 & 90.6 & 70.9 & 78.2 & & \\
\hline Neutral & 12.3 & 4.7 & 17.3 & 10.9 & & \\
\hline No & 9.6 & 4.7 & 11.8 & 10.9 & & \\
\hline 2) Shop Online & & & & & 9.07 & $.059 *$ \\
\hline Yes & 67.6 & 82.5 & 61.8 & 60.8 & & \\
\hline Neutral & 15.1 & 6.4 & 18.2 & 19.6 & & \\
\hline No & 17.3 & 11.1 & 20.0 & 19.6 & & \\
\hline 3) Self Checkout & & & & & 11.47 & $.022 * *$ \\
\hline Yes & 60.7 & 77.8 & 51.8 & 58.7 & & \\
\hline Neutral & 21.5 & 12.7 & 26.4 & 21.7 & & \\
\hline No & 17.8 & 9.5 & 21.8 & 19.6 & & \\
\hline 4) E-Airline Ticket & & & & & 2.92 & .571 \\
\hline Yes & 60.3 & 66.7 & 58.2 & 56.5 & & \\
\hline Neutral & 20.1 & 14.3 & 23.6 & 19.6 & & \\
\hline No & 19.6 & 19.0 & 18.2 & 23.9 & & \\
\hline 5) Pay Bills Online & & & & & 17.94 & $.001 * * *$ \\
\hline Yes & 57.5 & 79.4 & 48.2 & 50.0 & & \\
\hline Neutral & 27.9 & 15.9 & 33.6 & 30.4 & & \\
\hline No & 14.6 & 4.7 & 18.2 & 19.6 & & \\
\hline
\end{tabular}

When examining the Unconvinced Consumer, only Optimism and Discomfort were significant predictors of likelihood of Chinese consumers to use self-service technologies. Discomfort appears to be the strongest predictor of using new technology for this type of consumer (beta $=.272)$, followed closely by Optimism $($ beta $=$ .265). The levels of Insecurity and Innovativeness were not significant predictors of using self-service technology for this type of consumer. Surprisingly, no TRI dimensions were significant predictors of likelihood to use selfservice technology for the Adventurous Consumer. The TRI factors seemingly have little impact on whether this type of consumer uses self-service technology to complete retail transactions. 
Table 5

Predicting Likelihood of Using Self-Service Technology

\begin{tabular}{|c|c|c|c|c|c|}
\hline Consumer & TRI & Standardized & & & Sign. \\
\hline Type & Dimension & Beta & SE & t Value & Level \\
\hline \multicolumn{6}{|c|}{ Receptive Consumer } \\
\hline & Optimism & .348 & .202 & 2.424 & .019 \\
\hline & Innovativeness & .052 & .155 & .346 & .731 \\
\hline & Insecurity & -.341 & .159 & -2.708 & .009 \\
\hline & Discomfort & .293 & .185 & 2.268 & .027 \\
\hline \multicolumn{6}{|c|}{ Unconvinced Consumer } \\
\hline & Optimism & .265 & .129 & 2.757 & .007 \\
\hline & Innovativeness & .144 & .099 & 1.607 & .111 \\
\hline & Insecurity & -.037 & .116 & -.364 & .716 \\
\hline & Discomfort & .272 & .107 & 2.777 & .007 \\
\hline \multicolumn{6}{|c|}{ Adventurous Consumer } \\
\hline & Optimism & .167 & .311 & 1.096 & .279 \\
\hline & Innovativeness & -.124 & .247 & -.827 & .413 \\
\hline & Insecurity & .247 & .226 & -1.519 & .136 \\
\hline & Discomfort & -117 & .314 & -.714 & .479 \\
\hline
\end{tabular}

\section{DISCUSSION/IMPLICATIONS}

This research contributes to the understanding of factors affecting the diffusion of technology throughout China's retail environment. The findings should be useful to companies either entering or expanding into the retail marketplace in China, or other similar Asian markets. In many instances, the biggest challenge for companies introducing new technology throughout China is to get consumers to try it. The TRI dimensions (with the exception of Innovativeness) appear to be useful measures for assessing the likelihood of Chinese consumers using self-service technology to complete retail transactions.

Marketers need to take several steps to encourage Chinese consumers to use and adopt retail self-service technologies. Obviously, the first step is to make sure that Chinese consumers are aware that new self-service technologies are available to complete retail transactions. Research has shown that awareness of new technology is a critical missing piece for many potential users (Bitner et al., 2002). Despite repeated exposures and opportunities to learn about new technologies, many consumers still do not become aware of self-service options on a timely basis.

Chinese consumers must also understand the benefits of using the technology. Most consumers will not be prone to use the new technology unless they perceive a benefit from doing so. This is especially true for the Unconvinced consumers, who represented a disproportionate percentage of female consumers (72\%) compared to the overall sample percentage (66\%). Stressing benefits such as saving time, access to information, reducing transaction costs, or more control over the purchasing process could all be potential benefits that may motivate the Unconvinced consumer to use the new self-service technology. Pleasure derived from using the technology could even be a potential benefit. Bauer, Falk, and Hammerschmidt (2006) identified the importance of hedonic aspects in technology-dominated retail settings.

Unconvinced consumers also appear to be overly concerned with the potential loss of privacy. Marketers need to stress how safe the technology is with respect to protecting identity theft and preventing the selling of consumer information. The adoption of self-service technology should go smoother if the insecurity associated with using the new technology is reduced. In addition, emphasizing that behaviors, such as Internet shopping and online banking, are common practices for many consumers throughout the world should also help to reduce the anxiety of using the self-service technology.

Marketers must also reduce the discomfort level of the consumer. This appears to be very important for the Receptive consumers, who represent a slightly highly percentage of male consumers (43\%) compared to the overall sample percentage (34\%). Attention must be paid to ensure that self-service technologies are easy to use and are 
reliable. Consumers can't try something unless they know what to do. This type of consumer appears to be the most likely to try new self-service technologies in order to complete retail transactions.

Providing detailed information regarding how a specific technology-based retail transaction works should help in the decision-making process for these customers. Moreover, providing this additional information may enhance the trust the consumers have in the self-service technology. More informed consumers will also be able to discussion the different types of technology among themselves, which should also lead to a more rapid adoption of the self-service technology.

Even though the findings show that Adventurous consumers are not influenced by the four factors of technology readiness regarding their likelihood to use self-service technology, marketers would still be well advised to consider them in their marketing strategies. This group self-reports to be innovative, however, getting the Adventurous consumer to use new self-service technology early in the diffusion process is seemingly a critical step in the overall acceptance of the technology.

\section{CONCLUSION}

Self-service technology in China is likely to become increasingly more important as marketers strive to minimize costs and maximize service in order to remain competitive in this expanding marketplace. Marketers need to continually assess consumers' propensity to accept and use the new self-service technology that they offer. This study has examined technology readiness factors that may impact the willingness of different Chinese consumer types to use self-service technology to complete retail transactions. The levels of optimism, insecurity, and discomfort towards using new self-service technology appear to be either a contributor or an inhibitor to the diffusion of innovative self-service technology for most consumer types within the retail marketplace. Marketers need to take advantage of the contributor (Optimism) and address the inhibitors (Insecurity and Discomfort) in order to enhance the likelihood of Chinese consumers using self-service technology to complete retail transactions.

\section{LIMITATIONS AND FURTHER RESEARCH}

One limitation of this study relates to the sampling method. A convenience sample of Chinese college students was used, therefore generalizing the findings to the general Chinese consuming public should be done with care. A second limitation has to do with the scope of this study. Assessing and predicting the likelihood of using self-service technology is a complex issue. This study has provided limited insight into the relative importance of predictors of using technology to complete a retail transaction because only a small sampling of predictor factors was analyzed. A final limitation pertains to the measurement of "likelihood to use self-service technology." This study conceptualized the construct via a self-developed, five-item scale. Other dimensions of self-service technology exists that could have been included in the measurement.

Further studies should examine whether the relative importance of the dimensions of technology readiness differs across cultures. In addition, other predictors of propensity to use technology should be examined. Finally, future research could examine whether the relationship between the technology readiness dimensions and "likelihood to use self-service technology" will vary across demographic characteristics of consumers.

\section{AUTHOR INFORMATION}

Kevin M. Elliott is a Professor of Marketing at Minnesota State University, Mankato. He is also Co-Director of the MBA program at MSU, Mankato. He earned his PhD. in marketing from the University of Arkansas. His teaching interests include marketing strategy and sales management. His primary research interests are in the areas of technology readiness, online auctions, and cross-cultural marketing.

Juan (Gloria) Meng is an Assistant Professor of Marketing at Minnesota State University, Mankato. She earned her $\mathrm{PhD}$. in marketing from Southern Illinois University at Carbondale. Her teaching interests include marketing research, consumer behavior, and international marketing. Her primary research interests are in the areas of crosscultural consumer behavior, technology readiness, and services marketing. 


\section{REFERENCES}

1. Anderson, J.C. and Gerbing, D.W. (1988), Structural equation modeling in practice: A review and recommended two-step approach, Psychological Bulletin, 103 (3), 411-423.

2. Bauer, H.H., Falk, T. and Hammerschmidt, M. (2006), eTransQual: A transaction process-based approach for capturing service quality in online shopping, Journal of Business Research, 59 (7), 866-875.

3. Barczak, G.E., Pam S., and Pilling, B.K. (1997), Developing typologies of consumer motives for use of technologically based banking services, Journal of Business Research, 38, 131-139.

4. Bendapudi, N. and Leone, R.P. (2003), Psychological implications of customer participation in coproduction, Journal of Marketing, 67 (February), 14-28.

5. Bitner, M.J. Brown, S.W., and Meuter, M.L. (2000), Technology infusion in service encounters, Journal of the Academy of Marketing Science, 28 (1), 138-149.

6. Bitner, M.J., Brown, S.W. Ostrom, A.L., and Meuter, M.L. (2002), Implementing successful self-service technologies, Academy of Management Executive, 16 (4), 96-109.

7. Bobbitt, M.L. and Dabholkar, P.A. (2001), Integrating attitudinal theories to understand and predict use of technology-based self-service, International Journal of Service Industry Management, 12 (5), 423-450.

8. Boston Consulting Group (2007), Winning the hearts and minds of China's consumers," http://www.bcg.com/publications/files/Winning_Chinas_Consumers_Sept_2007.pdf.

9. Childers, T.L., Carr, C.L, Peck, J., and Carson, S. (2001), Hedonic and utilitarian motivations for online retail shopping behavior, Journal of Retailing, 77, 511-535.

10. Curran, J.M., Meuter, M.L., and Surprenant, C.F. (2003), Intentions to use self-service technologies: A confluence of multiple attitudes, Journal of Service Research, 5 (3), 209-224.

11. Dabholkar, P.A. (1996), Consumer evaluations of new technology-based self-service options: An investigation of alternative models of service quality, International Journal of_Research in Marketing, 13 (1), 29-51.

12. Dabholkar, P.A., and Bagozzi, R.P. (2002), An attitudinal model of technology-based self-service: Moderating effects of consumer traits and situational factors, Journal of the Academy of Marketing Science, 30 (3), 184-201.

13. Dabholkar, P.A., Bobbitt, M., and Lee, E.J. (2003), Understanding consumer motivation and behavior related to self-scanning in retailing: Implications for strategy and research on technology-based selfservice, International Journal of Service Industry Management, 14 (1), 59-95.

14. Davis, F.D. (1989), Perceived usefulness, perceived ease of use, and user acceptance of information technology, MIS Quarterly, 13 (3), 319-339.

15. Davis, F.D., Bagozzi, R.P., and Warshaw, P.R. (1989), User acceptance of computer technology: A comparison of two theoretical models, Management Science, 35 (8), 982-1003.

16. Davis, F.D., Bagozzi, R.P., and Warshaw, P.R. (1992), Extrinsic and intrinsic motivation to use computers in the workplace, Journal of Applied Social Psychology, 22 (14), 1109-1130.

17. Ellen, P.S., Bearden, W.O., and Sharma, S. (1991), Resistance to technological innovations: An examination of the role of self-efficacy and performance satisfaction, Journal of the Academy of Marketing Science, 19 (4), 297-307.

18. Erumban, A.A. and de Jong, S.B. (2006), Cross-country differences in ICT adoption: A consequence of culture?, Journal of World Business, 41, 302-314.

19. Gilly, M.C. and Zeithaml, V.A. (1985), The elderly consumer and adoption of technologies, Journal of Consumer Research, 12 (December), 353-357.

20. International Herald Tribune (2007), China Says Economy Still Growing Fast, October 24, http://www.iht.com/articles/ap/2007/10/25/business/AS-FIN-ECO-China-Economy.php.

21. Hsieh, A.T., Yen, C.H. and Chin, K.C. (2004), Participative customers as partial employees and service provider workload, International Journal of Service Industry Management, 15 (2), 187-199.

22. Hofstede, G. (1980), Culture's Consequences: International Differences in Work Related Values, Sage: Beverly Hills, CA.

23. Hofstede, G. (2001), Culture's Consequences: Comparing Values, Behaviors, Institutions, and Organizations Across Nations, Sage: Thousand Oaks, CA. 
24. Lee, I., Choi, B., Kim, J. and Hong, S.J. (2007), Culture-technology fit: Effects of cultural characteristics on the post-adoption beliefs of mobile internet users, International Journal of Electronic Commerce, 11 (4), 11-51.

25. Leo, C., Bennett, R. and Hartel, C. E. J. (2005), Cross-cultural differences in consumer decision-making styles, Cross Cultural Management, 12 (3), 32-62.

26. Lin, C.H., Shih, H.Y. and Sher, P.J. (2007), Integrating technology readiness into technology acceptance: The TRAM model, Psychology \& Marketing, 24 (7), 641-657.

27. Lindsay, R.M. and Ehrenberg, A.S.C. (1993), The design of replicated studies," The American Statistian, 47 (3), 217-228.

28. McDonald, H., Corkindale, D. and Sharp, B. (2003), Behavioral versus demographic predictors of early adoption: A critical analysis and comparative test, Journal of Marketing Theory \& Practice, 11 (3), 84-92.

29. McKinsey Group (2006), Made in china to sold in China: The rise of the Chinese urban consumer, http://www.mckinsey.com/mgi/publications/china_consumer/.

30. Mearian, L. (2001), Staples installing Internet kiosks in all U.S. retail stores, Computerworld, January 30 , $1-3$.

31. Meuter, M.L., Ostrom, A.L., Roundtree, R.I., and Bitner, M.J. (2000), Self service technologies: understanding customer satisfaction with technology-based service encounters, Journal of Marketing, 64 (July), 50-64.

32. Meuter, M.L., Ostrom, A.L., Bitner, M.J., and Roundtree, R.I. (2003), The influence of technology anxiety on consumer use and experiences with self-service technologies, Journal of Business Research, 56 (11), 899-906.

33. Meuter, M.L., Bitner, M.J., Ostrom, A.L., and Brown S.W. (2005), Choosing among alternative service delivery modes: An investigation of customer trial of self-service technologies, Journal of Marketing, 69 (2), 61-83.

34. Mick, D.G. and Fournier, S. (1998), Paradoxes of technology: Consumer cognizance, emotions, and coping strategies, Journal of Consumer Research, 25 (September), 123-147.

35. Parasuraman, A. (2000), Technology readiness index (TRI): A multiple-item scale to measure readiness to embrace new technologies, Journal of Service Research, 2 (4), 307-320.

36. Parasuraman, A. and Colby, C.I. (2001), Techno-Ready Marketing, Free Press: New York.

37. Rogers, E. (1995), Diffusion of Innovations, Free Press: New York.

38. Singh, S. (2006), Cultural differences in, and influences on, consumers' propensity to adopt innovations, International Marketing Review, 23 (2), 173-191.

39. Srite, M. and Karahanna, E. (2006), The role of espoused national cultural values in technology acceptance, MIS Quarterly, 30 (3), 679-704.

40. Szymanski, D.M. and Hise, R.T. (2000), E-satisfaction: An initial examination, Journal of Retailing, 76 (3), 309-322.

41. Tsikriktsis, N. (2004), A technology readiness-based taxonomy of customers: A replication and extension, Journal of Service Research, 7 (1), 42-52.

42. Venkatesh, V. (2000), Determinants of perceived ease of use: Integrating control, intrinsic motivation, and emotion into the technology acceptance model, Information Systems Research, 11 (4), 342-365.

43. Walker, R.H., Craig-Lees, M., Hecker, R. and Francis, H. (2002), Technology-enables service delivery: An investigation of reason affecting customer adoption and rejection, International Journal of Service Industry Management, 13 (1), 91-106.

44. Weijters, B., Rangarajan, D., Falk, T., and Schillewaert, N. (2007), Determinants and outcomes of customer use of self-service technology in a retail setting, Journal of Service Research, 10 (1), 3-21. 


\section{APPENDIX}

Technology Readiness Index

\section{Instructions - (Please circle your answer)}

The following are statements concerning peoples' beliefs about technology at their work. For each statement, please indicate whether you "strongly agree" (5), "somewhat agree" (4), are "neutral" (3), "somewhat disagree" (2), or "strongly disagree" (1).

1. Technology gives people more control over their daily lives.

\section{Strongly \\ Agree}

5

2. The human touch is very important when doing business with a company.

3. Other people come to me for advice on new technologies.

4. Technical support lines are not helpful because they don't explain things in terms I understand.

5. Sometimes, I think that technology systems are not designed for use by ordinary people.

6. Products and services that use the newest technologies are much more convenient to use.

5 person rather than a machine.

8. I prefer to use the most advanced technology available.

10. I like the idea of doing business via computers because I am not limited to regular business hours.

11. If I provide information to a machine or over the Internet, I can never be sure it really gets to the right place.

12. When I get technical support from a provider of a high-tech product or service, I sometimes feel as if I am taken advantage of by someone who knows more than I do.
Somewhat Strongly Disagree Disagree

$$
2
$$

2 1

21

21




\section{Strongly Somewhat Neutral \\ Agree \\ Agree}

Somewhat Strongly

Disagree Disagree

14. I do not consider it safe giving out a credit card number over a computer.

15. It seems my friends are learning more about the newest technologies than I am.

16. If I buy a high-tech product or service, I prefer to have the basic model over one with a lot of extra features.

17. Technology makes me more efficient in my occupation.

18. I do not consider it safe to do any kind of financial business online.

19. In general, I am among the first in my circle of friends to acquire new technology when it appears. 5

20. It is embarrassing when I have trouble with a high-tech gadget while people are watching.

21. I find new technologies to be mentally stimulating. 5

22. There should be caution in replacing important people-tasks with technology because new technology can break-down or get disconnected.

23. I can usually figure out new high-tech products and services without help from others.

24. I worry that information I send over the Internet will be seen by other people.

25. Technology gives me more freedom of mobility.

26. Many new technologies have health or safety risks that are not discovered until after people have used them.

27. I keep up with the latest technological developments in my areas of interest.

28. I do not feel confident doing business with a place that can only be reached online.

29. Learning technology can be as rewarding as the technology itself.

30. Any business transaction I do electronically should be confirmed later with something in writing. 
31. I enjoy the challenge of figuring out high-tech gadgets.

5

$4 \quad 3$

2

1

32. New technology makes it too easy for governments and companies to spy on people.

5

4

3

2

1

33. I feel confident that machines will follow through with what I instructed them to do.

5

4

3

2

1

34. Whenever something gets automated, I need to check carefully that the machine or computer is not making mistakes.

3

2

1

35. I find I have fewer problems than other people in making technology work for me.

5

4

3

2

1

36. Technology always seems to fail at the worst possible time.

$5 \quad 4 \quad 3 \quad 2$

2

1

* These questions comprise the Technology Readiness Index, which is copyrighted by A. Parasuraman and Rockbridge Associates, Inc., 1999. This scale may be duplicated only with permission from the authors. 